\title{
BMJ Open Needs and rights awareness of stroke survivors and caregivers in urban and rural China: a cross-sectional, multiple- centre questionnaire survey
}

\author{
Xiaoshuang Xia, ${ }^{1}$ Xiaolin Tian, ${ }^{1}$ Tianli Zhang, ${ }^{1}$ Peilu Wang, ${ }^{1}$ Yanfen Du, ${ }^{1}$ \\ Chunru Wang, ${ }^{2}$ Zhiqiang Wei, ${ }^{1}$ Guojing Jiang, ${ }^{3}$ Qiong Cheng, ${ }^{4}$ Qiang Li, ${ }^{5}$ \\ Jinpeng Li, ${ }^{6}$ Qingling Wang, ${ }^{7}$ Qi Dong, ${ }^{1}$ Xiaobin Guo, ${ }^{8}$ Meihua Sun, ${ }^{9}$ Lin Wang, ${ }^{10}$ \\ Ming Liu, ${ }^{11}$ Xin Li ${ }^{\oplus 1}$
}

To cite: Xia X, Tian X, Zhang $T$, et al. Needs and rights awareness of stroke survivors and caregivers in urban and rural China: a crosssectional, multiple-centre questionnaire survey. BMJ Open 2019;9:e021820. doi:10.1136/ bmjopen-2018-021820

- Prepublication history for this paper is available online. To view these files please visit the journal online (http://dx.doi org/10.1136/bmjopen-2018021820).

$\mathrm{XX}$ and $\mathrm{XT}$ contributed equally.

Received 22 January 2018 Revised 9 February 2019 Accepted 14 February 2019

D Check for updates

(c) Author(s) (or their employer(s)) 2019. Re-use permitted under CC BY-NC. No commercial re-use. See rights and permissions. Published by BMJ.

For numbered affiliations see end of article.

\section{Correspondence to}

Professor Xin Li;

lixinsci@126.com and Ming Liu; wyplmh@hotmail.com

\section{ABSTRACT}

Objectives Stroke survivors require assistance and support in their daily lives. This survey aims to investigate the needs and rights awareness in Chinese stroke survivors and caregivers in rural and urban settings. Setting This survey was adapted from the one created by the World Stroke Organization. The questionnaire included demands for psychological support, treatment and care, social support and information. From January 2015 to January 2016, the survey was pilot tested with urban and rural-dwelling stroke survivors and caregivers from 12 hospitals. Stroke survivors were invited to participate if they were over 18 years old and had experienced a stroke. Exclusion criteria were patients who had disorders of consciousness, significant cognitive impairment, aphasia, communication difficulties or psychiatric disorders. Only caregivers who were family members of the patients were chosen. Paid caregivers were excluded.

Participants One thousand, one hundred and sixty-seven stroke survivors and 1119 caregivers were enrolled.

Primary outcome measures The needs of stroke survivors and caregivers in rural and urban areas were compared. The correlations between needs of rural and urban stroke survivors and caregivers and potential effect factors were analysed, respectively.

Results Among the cohort, $93.5 \%$ reported the need for psychological support, $88.6 \%$ for treatment and care, $84.8 \%$ for information and $62.7 \%$ for social support. The total needs and each aspect of needs of stroke survivors in urban settings were greater than of those in rural settings $(p<0.01)$. In rural areas, total needs and each aspect of needs were positively correlated with education level $(p<0.01)$.

Conclusions Needs and rights awareness of stroke survivors should also be recognised in both urban and rural China. According to the different needs of patients and their caregivers, regional and individualised services were needed by stroke survivors and their caregivers.

\section{INTRODUCTION}

The absolute number of people who have strokes increased annually, as well as related

\section{Strengths and limitations of this study}

- Multiple-centre study of needs and rights awareness have not been reported in China.

- The breadth of the evidence collected including stroke survivors and their caregivers, and then the comparison is made in urban settings and rural settings.

- The needs and rights awareness of stroke survivors and their caregivers involves demands for psychological support, treatment and care, social support and information.

- Limitations include potential bias due to the exclusion of patients with severe language or cognitive impairment. The number of participants was also limited.

deaths and disability-adjusted life-years lost. ${ }^{12}$ Stroke survivors have reported that their quality of life (QoL) after stroke is poor. ${ }^{3}$ Therefore, it is important to know what stroke survivors and caregivers need. Surveys of stroke survivors have reported unmet needs in several domains, such as care, communication, information provision and managing stroke-related problems. ${ }^{45}$ Less is known about the comprehensive analysis of different components and extent of patients' needs. To frame a global bill of rights for stroke patients, the World Stroke Organization (WSO) has launched an online survey to determine what stroke survivors and caregivers require in the worldwide. (https:// www. surveymonkey.com/s/WSOStrokeSurvivor-Chinese and https://www.surveymonkey.com/s/WSOStrokeCarer-Chinese). On the basis of this, the Global Stroke Bill of Rights developed by the WSO, sets out the rights of each stroke survivor to receive 
the best stroke care, be informed and prepared, and be supported in their recovery. ${ }^{6}$

The opinions from China, a country with a large number of stroke patients in which the healthcare system may be different from that in Europe or Australia seems to be indispensable. The Chinese government has been taking several important steps addressing the challenges of stroke care and prevention, including conducting training and public stroke education, establishing standardised therapies and protocols, and networking with community hospitals. ${ }^{7}$ A community-based stroke system of care and an educational campaign, which was developed in three townships in China, was proved to be effective and practical for optimising stroke treatments and improving patient outcomes. ${ }^{8}$ Our previous single-centre study found that the high demands were eagerly reported by most stroke survivors. ${ }^{9}$ This multiple-centre survey aims to further investigate the needs and rights awareness in Chinese stroke survivors and caregivers in rural and urban settings, which could provide a reference for the improvement of the stroke-related health service system, providing stroke survivors with the greatest chance of a good recovery and a healthier, more productive and independent life.

\section{METHODS}

\section{Study population}

From January 2015 to January 2016, the consecutive stroke survivors and caregivers from the Stroke Clinical Registry and Follow-up Database of 12 hospitals were invited to participate in the study when they were followed to the hospital. According to the Kendall sample size determination method of the questionnaire, at least 70-140 samples for each group were needed; therefore, we recruited more participants than the sample size determined. Eligibility criteria for stroke survivors were: (1) aged 18years or over; (2) a clinical and imaging diagnosis of stroke; (3) able to complete the survey with or without help from caregivers and (4) agreed to participate in the study. Exclusion criteria were patients who had disorders of consciousness, significant cognitive impairment, aphasia, communication difficulties or psychiatric disorders. Caregivers who had been taking care of the stroke patients including those unable to come to the hospital in the Stroke Clinical Registry and Follow-up Database were recruited. Only caregivers who were family members of the patients were chosen. Paid caregivers were excluded.

\section{Patient and public involvement}

The patients in our study were not involved in the development of the research question and outcome measures, the recruitment of subjects and the undertaking of the study. Each participant received a report describing the results of our study.

\section{Survey development}

The questionnaire was adapted from the Chinese version that was designed by the WSO. The questionnaire consisted of four general questions and 14 questions about the needs and rights awareness of stroke survivors. The general questions included age, gender, level of education and time since the first stroke. The clinical data including stoke type and National institutes of Health Stroke Scale (NIHSS) score were collected. The other 14 questions included demands for prompt and effective treatment, information about stroke, and psychological and social support. The stroke caregivers questionnaire includes 14 questions about the needs that they believe the patients had. Fourteen of the questions had five choices for each question. The five choices were strongly agree, agree, neutral, disagree and strongly disagree. The Likert 5-grade score method was used to assign 1-5 points; higher scores indicated a greater degree of demand.

Stroke survivors and caregivers were interviewed face to face during the patients' follow-up by well-trained neurologists who were not the patients' treating doctors. The purpose of the survey and the procedure was explained fully to all participants.

\section{Statistical analysis}

Continuous variables are presented as mean \pm SD. Frequencies and proportions were used to summarise levels of answers. The Spearman Rank Correlation Coefficient was used to analyse the correlations between levels of needs and potential associated factors. Levels of different needs were compared between rural and urban. Categorical variables are displayed as frequencies and percentages. Continuous variables were analysed using t-test. Categorical variables were analysed using a $\chi^{2}$ test. Comparisons between groups were made using the Mann-Whitney U test. $\mathrm{P}$ value at 0.05 were considered significant.

\section{RESULTS}

\section{Study population}

The descriptive characteristics of stroke survivors and caregivers were summarised in tables 1 and 2.

A total of 2286 stroke survivors and caregivers completed the survey, including 1167 stroke survivors and 1119 caregivers. The 1167 stroke survivors included 446 women and 721 men with a mean age of $(65.39 \pm 10.94)$. Of these patients, $517(44.3 \%)$ stroke survivors dwelt in urban locations, while $650(55.7 \%)$ dwelt in rural locations. Five hundred sixty-seven $(48.6 \%)$ patients experienced their first stroke within 1 year and $323(27.7 \%)$ patients had more than 9 years of education.

The 1119 caregivers included 522 women and 597 men, with a mean age of $(47.96 \pm 12.3)$. The duration of care for $452(40.4 \%)$ of the patients was less than 1 year, and 649 $(58.0 \%)$ caregivers had more than 9 years of education.

The stroke survivors and caregivers in urban areas were older than those in rural areas $(\mathrm{p}<0.001)$. Time since the first stroke in rural-dwelling stroke survivors was shorter 
Table 1 Characteristics of stroke survivors

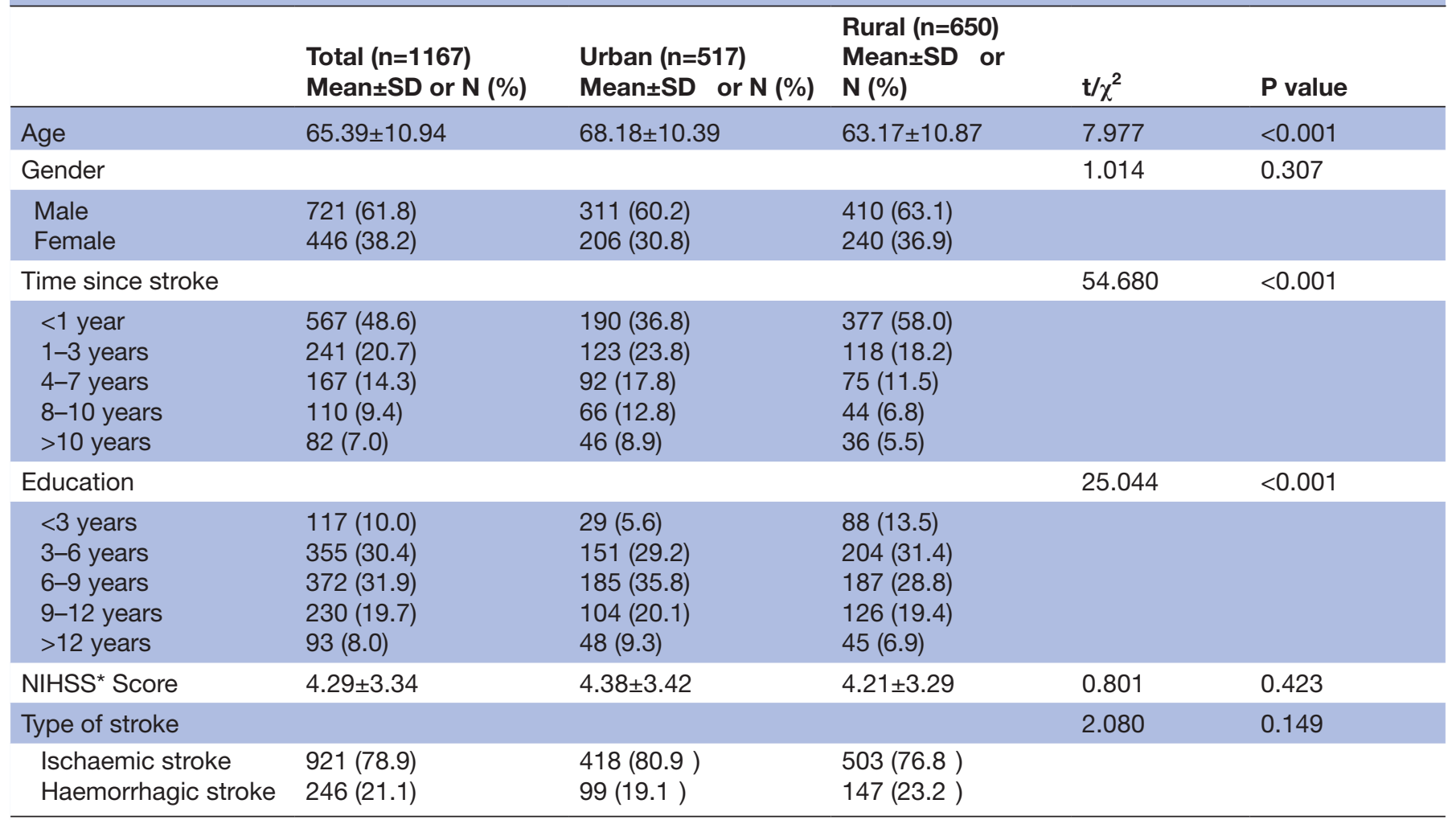

${ }^{*}$ NIHSS: National institutes of Health Stroke Scale

t-test or $\chi^{2}$ test was used to compare characteristics of stroke survivors in urban and rural settings.

than that in urban-dwelling stroke survivors, while education level was higher in stroke survivors and caregivers in urban areas. There was no difference in the NIHSS score between the two groups.

\section{Needs of total stroke survivors and caregivers}

The participants reported needs for psychological support $(93.5 \%)$, treatment and care $(88.6 \%)$, information $(84.8 \%)$ and social support $(62.7 \%)$. Total needs and each aspect of needs were positively correlated with education level $(p<0.05)$. The results of the survey showed that caregivers prioritised the needs for information $(94.5 \%)$, psychological support $(92.3 \%)$, treatment and care $(88.1 \%)$ and social support $(76.2 \%)$. These were also positively correlated with levels of education $(\mathrm{p}<0.05)$. The scores of needs about that is shown in table 3 .

\section{Needs in urban and rural areas}

The total needs and each aspect of needs in stroke survivors in urban areas were greater than of those in rural areas (table 4 , figure 1 ).

There was no correlation between the needs and age, gender, education level or time since the first stroke in patients from urban areas $(\mathrm{p}>0.05)$. In rural patients, total needs and each aspect of needs were positively correlated with education level $(\mathrm{p}<0.01)$. The needs for information, social supports and treatment and care were negatively correlated with age $(\mathrm{p}<0.01)$. Among rural patients, men had greater needs for information, social supports, and treatment and care than women (table 5).

\section{DISCUSSION}

The questionnaire was tested again for the reliability in our population. The scales reliability of the stroke survivors' questionnaire was assessed with a total Cronbach's $\alpha$ of 0.906 , corrected by inter-item correlation above 0.70 . The scales reliability of the stroke caregivers' questionnaire was assessed with a total Cronbach's $\alpha$ of 0.927 , corrected by inter-item correlation above 0.70 . The Cronbach's $\alpha$ values were good for all scales for the study.

This survey investigated the needs of Chinese stroke survivors and caregivers in rural and urban settings. Patients and their caregivers had high demands for psychological support, treatment and care, social support and information. Of the above, psychological support was needed the most.

\section{Needs of stroke survivors}

In our study, stroke survivors in China had the strongest demand for psychological support. A survey in Australia found that emotional needs were less likely to be fully met than physical needs. ${ }^{4}$ Psychological distress after stroke is common, as a result of its sudden onset and the potential loss of physical activity. ${ }^{10}$ Some surveys have demonstrated that emotional problems among stroke survivors would 
Table 2 Characteristics of stroke caregivers

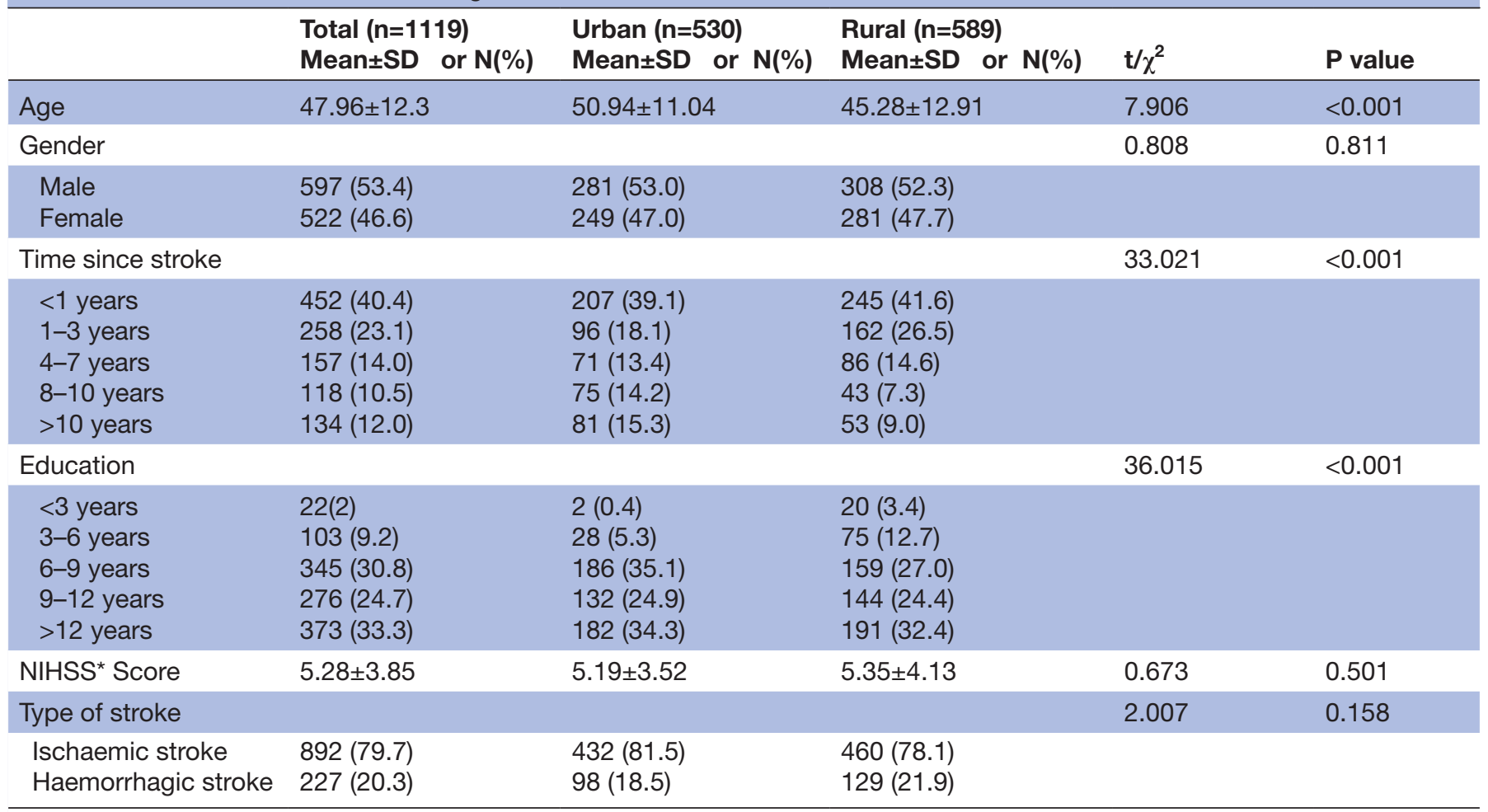

${ }^{*}$ NIHSS: National institutes of Health Stroke Scale

t-test or $\chi^{2}$ test was used to compare characteristics of stroke survivors in urban and rural settings.

be prejudicial to the treatment and rehabilitation of these patients after stroke. ${ }^{11-14}$ Only $10 \%$ of the respondents of one study who suffered from emotional problems had received support from a community psychological service. ${ }^{15}$ The newest version of the Chinese Stroke Guidelines goes further, recommending psychological support to patients after stroke. A multi-perspective, qualitative study suggests that psychological support, including not only formal provision, but also information, advice and peer or social support, should be supplied to stroke survivors. ${ }^{10}$

The needs for treatment and care were second only to the need for psychological support. As stroke is an emergent and disastrous disease, timely and appropriate therapy is vital to patient survival and recovery. Long-term individualised and optimised treatment and care are also needed to prevent recurrent stroke and improve patients' QoL. ${ }^{16}$

Table 3 Needs of total stroke survivors and caregivers

\begin{tabular}{|c|c|c|}
\hline & Stroke survivors & Stroke caregivers \\
\hline Total & $4.5(4.0-4.9)$ & $4.8(4.4-5.0)$ \\
\hline $\begin{array}{l}\text { Psychological } \\
\text { support }\end{array}$ & $4.5(4.0-5.0)$ & $5.0(4.5-5.0)$ \\
\hline Information & $4.5(4.0-5.0)$ & $5.0(4.5-5.0)$ \\
\hline Treatment and care & $4.5(4.0-5.0)$ & $4.8(4.4-5.0)$ \\
\hline Social support & $4.2(4.0-4.8)$ & $4.6(4.2-5.0)$ \\
\hline
\end{tabular}

Needs for knowledge about stroke were also reported by most stroke survivors. A previous study showed that knowledge about stroke warning signs and risk factors was very poor in stroke survivors in China, and only $9.2 \%$ reported calling for emergency services. ${ }^{17}$ With that knowledge, stroke survivors could better understand the disease, helping them to rehabilitate and prevent stroke recurrence.

A survey in China showed that physical and services barriers restrict stroke survivors' participation in social activity. ${ }^{18}$ Financial support was also needed by stroke survivors to maintain their treatment, care and activities of daily life. ${ }^{15}$ Social security systems for stroke survivors need to be improved in developing countries such as China.

Table 4 Needs of stroke survivors in urban and rural settings

\begin{tabular}{lllll}
\hline & Urban & Rural & Z & p \\
\hline Total & $4.7(4.2-4.9)$ & $4.2(4.0-4.7)$ & -8.402 & $<0.001$ \\
$\begin{array}{l}\text { Psychological } \\
\text { support }\end{array}$ & & & & \\
Information & $5.0(4.0-5.0)$ & $4.5(4.0-5.0)$ & -5.685 & $<0.001$ \\
$\begin{array}{l}\text { Treatment } \\
\text { and care }\end{array}$ & $5.0(4.4-5.0)$ & $4.4(4.0-4.8)$ & -10.795 & $<0.001$ \\
$\begin{array}{l}\text { Social } \\
\text { support }\end{array}$ & $4.6(4.0-4.8)$ & $4.0(3.8-4.6)$ & -9.771 & $<0.001$ \\
\hline
\end{tabular}




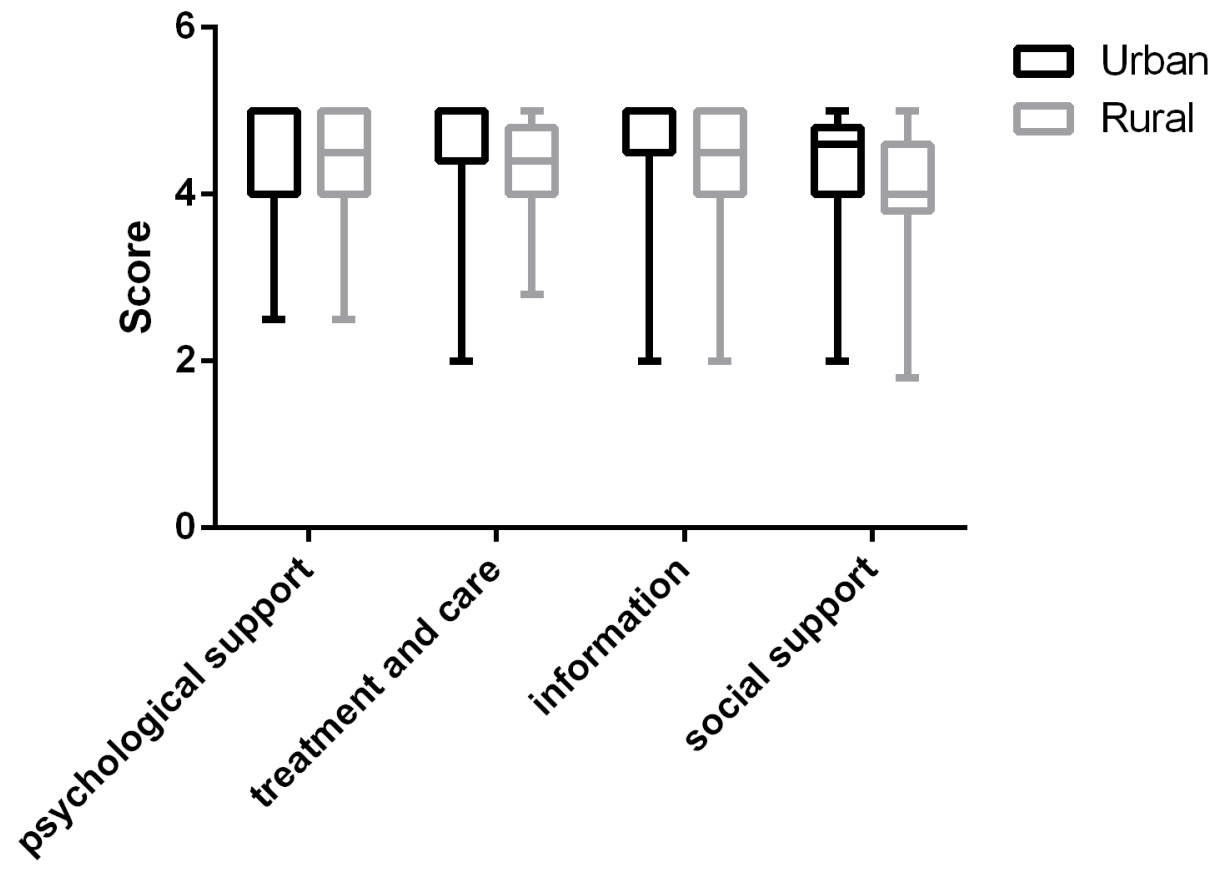

\section{Needs of stroke survivors in urban and rural settings}

Figure 1 The total needs and each aspect of needs in stroke survivors in urban areas were greater than of those in rural areas $(p<0.001)$.

In this survey, we found that needs were positively correlated with the level of education. The reason could be that the patients of higher education had more awareness of patients' rights. ${ }^{19}$

\section{The stroke caregivers' opinions}

Not consistent with the stroke survivors, caregivers were ultimately concerned with obtaining information. A longitudinal study of caregivers' perspectives found that family caregivers expected to obtain assistance and related care information. ${ }^{20}$ It is equally important that caregivers acquire knowledge of prevention and control of disease.

\section{Needs in urban and rural settings}

The stroke survivors who lived in urban settings were older than those in rural settings; as shown in a study in China, the age at onset of stroke in patients living in urban areas was higher than that in rural areas. ${ }^{21}$ Among stroke

\begin{tabular}{|c|c|c|c|c|}
\hline & Male & Female & $\mathbf{Z}$ & $p$ \\
\hline Total & $4.3(4.0-4.8)$ & $4.1(3.9-4.1)$ & -3.194 & 0.001 \\
\hline $\begin{array}{l}\text { Psychological } \\
\text { support }\end{array}$ & $4.5(4.0-5.0)$ & $4.0(4.0-5.0)$ & -1.727 & 0.084 \\
\hline Information & $4.5(4.0-5.0)$ & $4.0(3.5-4.5)$ & -3.275 & 0.001 \\
\hline $\begin{array}{l}\text { Treatment and } \\
\text { care }\end{array}$ & $4.6(4.0-5.0)$ & $4.2(4.0-4.8)$ & -2.972 & 0.003 \\
\hline Social support & $4.1(3.8-4.6)$ & $4.0(3.6-4.6)$ & -2.102 & 0.036 \\
\hline
\end{tabular}

survivors in rural settings, $58.0 \%$ experienced their first stroke within 1 year. There was a remarkable, decreasing trend in stroke mortality in urban areas, which is mainly observed in the elderly population, but with little change in rural areas ${ }^{22}$

A survey in Korea found that QoL was significantly lower for stroke patients in rural areas compared with those in urban areas. ${ }^{23}$ The needs and rights awareness of stroke survivors in rural settings were not as strong as for those in urban settings. Data from a sample of urban and rural community cohorts observed that a rural advantage for psychological QoL compared with urban participants. ${ }^{24}$ That may be part of the reason for less psychological needs in rural areas. However, a study of suicide ideation in acute ischaemic stroke patients in China showed that suicide ideation was more frequent in patients who lived in rural regions. ${ }^{25}$ This is a reminder that the psychological needs of stroke survivors in rural populations should not be ignored.

Compared with those from urban areas, individuals from rural areas were less likely to receive stroke unit care, brain and carotid imaging, or inpatient rehabilitation. ${ }^{26}$ Sustained use of secondary prevention medications is low in individuals who live in rural areas. ${ }^{27}$ As a study in China has shown, the prevalence of hypertension was higher, but awareness, treatment and control were lower in rural than urban residents. ${ }^{28}$ Future work should focus on improving stroke interventions and care in rural areas. The Rural Stroke Project in Australia, which invested in clinical coordinators who implemented 
organisational change, together with increased clinician resources, effectively improved care of stroke patients in rural hospitals. ${ }^{29}$

The knowledge of stroke among patients is unsatisfactory, particularly among those in rural areas. ${ }^{3031}$ A nationwide survey in China showed that individuals living in rural areas were less likely to have knowledge of transient ischaemic attack. ${ }^{32}$ A lower educational level was found in rural survivors in this study, which was consistent with the results of other studies. ${ }^{243}$ In an Irish survey, those who had only a primary level of education had the least understanding of stroke. ${ }^{34}$ Some strategies have been used to raise the knowledge of stroke in rural settings, such as educational flyers, ${ }^{35}$ television ${ }^{36}$ and a community-specific public education campaign. ${ }^{37}$

Patients in rural area were more likely to be fully retired due to ill-health. ${ }^{38}$ Physical/structural and services/assistance barriers were considered the dominant barriers to activity and participation for stroke survivors in the rural areas of China. ${ }^{18}$ Poorer QoL was associated with reduced social interaction. ${ }^{39}$ The new rural cooperative medical system had some impact on reducing catastrophic medical payments associated with these diseases, but improvement of the reimbursement rate is necessary to further improve the system's effectiveness. ${ }^{40}$

\section{Limitation}

Patients who had severe language or cognitive impairment were excluded in the present study, leading to some bias against patients who could not express their views.

\section{CONCLUSION}

Needs regarding psychological support, treatment and care, social support and information in both rural and urban stroke patients, and in caregivers, were strong. Public health organisations and decision makers should not neglect the needs of stroke survivors. Stroke services should consider each stroke survivor's needs for psychological and physical care, starting from the onset of stroke all the way through rehabilitation and reintegration into the community, which require a more concerted effort across specialists in stroke units, communities and social supports.

\footnotetext{
Author affiliations

${ }^{1}$ Neurology, The Second Hospital of Tianjin Medical University, Tianjin, China

${ }^{2}$ Neurology, Ning He Hospital of Tianjin, Tianjin, China

${ }^{3}$ Neurology, The Bronch of Tianjin City No.3 Center Hospital, Tianjin, China

${ }^{4}$ Neurology, Da Gang Hospital of Tianjin, Tianjin, China

${ }^{5}$ Neurology, Port Hospital of Tianjin, Tianjin, China

${ }^{6}$ Neurology, Binhai Hospital, Tianjin Medical University General Hospital, Tianjin,

China

${ }^{7}$ Medicine, XiangYang Community Medical Service Center of Tianjin Binhai New

Area, Tianjin, China

${ }^{8}$ Neurology, The Second Hospital of Tangshan, Tangshan, China

${ }^{9}$ Neurology, Teng Zhou Central People's Hospital, Tengzhou, China

${ }^{10}$ Geratology, The Second Hospital of Tianjin Medical University and Tianjin Geriatric Institute, Tianjin, China

${ }^{11}$ Stroke Clinical Research Unit, Department of Neurology, West China Hospital,

Sichuan University, Chengdu, China
}

Acknowledgements The authors would like to acknowledge the World Stroke Organization (WSO), which allowed us to adapt the questionnaire about the rights of stroke survivors and caregivers. We acknowledge the multicentre groups have conducted the work. We thank all the patients involved in this study for their cooperation and support.

Contributors XX conceived the study and wrote the manuscript. XT helped to conceive the study. XL contributed significantly to design the study and revise manuscript. ML contributed to the conception of the study and revised the manuscript. XL and $M L$ are co-correspondence authors. TZ helped the data analyses. PW, YD, CW, ZW, GJ, QC, QL, JL, QW, QD, XG and MS collected the data from the survey. LW helped perform the analysis with constructive discussions. All authors reviewed the manuscript.

Funding This work was supported by the key project in the Science and Technology Foundation of Tianjin Health and Family Planning [15KG136], the Natural Science Foundation of Tianjin [16JCYBJC25500] and Tianjin science and technology plan projects [17KPHDSF00170].

Competing interests None declared.

Patient consent for publication Not required.

Ethics approval This study was approved by our local Ethics Committee at the Second Hospital of Tianjin Medical University. Individual ethics approval was obtained from the ethics committee responsible for each of the hospitals that participated in this survey.

Provenance and peer review Not commissioned; externally peer reviewed.

Data sharing statement № additional unpublished data are available.

Open access This is an open access article distributed in accordance with the Creative Commons Attribution Non Commercial (CC BY-NC 4.0) license, which permits others to distribute, remix, adapt, build upon this work non-commercially, and license their derivative works on different terms, provided the original work is properly cited, appropriate credit is given, any changes made indicated, and the use is non-commercial. See: http://creativecommons.org/licenses/by-nc/4.0/.

\section{REFERENCES}

1. Feigin VL, Roth GA, Naghavi M, et al. Global burden of stroke and risk factors in 188 countries, during 1990-2013: a systematic analysis for the Global Burden of Disease Study 2013. Lancet Neurol 2016;15:913-24.

2. Benjamin EJ, Blaha MJ, Chiuve SE, et al. Heart Disease and Stroke Statistics-2017. Circulation 2017;135:e146-603.

3. De Wit L, Theuns P, Dejaeger E, et al. Long-term impact of stroke on patients' health-related quality of life. Disabil Rehabil 2017;39:1-6.

4. Andrew NE, Kilkenny M, Naylor R, et al. Understanding longterm unmet needs in Australian survivors of stroke. Int J Stroke 2014;9(Suppl A100):106-12.

5. Kruithof WJ, Post MW, van Mierlo ML, et al. Caregiver burden and emotional problems in partners of stroke patients at two months and one year post-stroke: Determinants and prediction. Patient Educ Couns 2016;99:1632-40.

6. site. RTWsow. http://www.world-stroke.org/newsletter/latestupdates/18-news/latest-updates/261-toolkit-for-the-global-bill-ofrights. [Accessed 23 November, 2015].

7. Liu L, Wang D, Wong KS, et al. Stroke and stroke care in China: huge burden, significant workload, and a national priority. Stroke 2011;42:3651-4.

8. He M, Wang J, Dong Q, et al. Community-based stroke system of care improves patient outcomes in Chinese rural areas. J Epidemiol Community Health 2018;72:630-5.

9. Li X, Xia X, Wang P, et al. Needs and rights awareness of stroke survivors and caregivers: a cross-sectional, single-centre questionnaire survey. BMJ Open 2017;7:e013210.

10. Harrison M, Ryan T, Gardiner C, et al. Psychological and emotional needs, assessment, and support post-stroke: a multi-perspective qualitative study. Top Stroke Rehabil 2017;24:1-7.

11. Chau JP, Thompson DR, Chang AM, et al. Depression among Chinese stroke survivors six months after discharge from a rehabilitation hospital. J Clin Nurs 2010;19(21-22):3042-50.

12. Ekstam L, Johansson U, Guidetti S, et al. The combined perceptions of people with stroke and their carers regarding rehabilitation needs 1 year after stroke: a mixed methods study. BMJ Open 2015;5:e006784.

13. Matsuzaki S, Hashimoto M, Yuki S, et al. The relationship between post-stroke depression and physical recovery. J Affect Disord 2015;176:56-60. 
14. Park GY, Im S, Oh CH, et al. The association between the severity of poststroke depression and clinical outcomes after first-onset stroke in Korean patients. Gen Hosp Psychiatry 2015;37:245-50.

15. Walsh $M E$, Galvin R, Loughnane $C$, et al. Community re-integration and long-term need in the first five years after stroke: results from a national survey. Disabil Rehabil 2015;37:1834-8.

16. Miller EL, Murray L, Richards L, et al. Comprehensive overview of nursing and interdisciplinary rehabilitation care of the stroke patient: a scientific statement from the American Heart Association. Stroke 2010;41:2402-48.

17. Zeng Y, He GP, Yi GH, et al. Knowledge of stroke warning signs and risk factors among patients with previous stroke or TIA in China. $J$ Clin Nurs 2012;21(19-20):2886-95.

18. Zhang L, Yan T, You L, et al. Barriers to Activity and Participation for Stroke Survivors in Rural China. Arch Phys Med Rehabil 2015;96:1222-8.

19. Yaghobian M, Kaheni S, Danesh M, et al. Association between awareness of patient rights and patient's education, seeing bill, and age: a cross-sectional study. Glob J Health Sci 2014;6:55-64.

20. Tsai PC, Yip PK, Tai JJ, et al. Needs of family caregivers of stroke patients: a longitudinal study of caregivers' perspectives. Patient Prefer Adherence 2015;9:449-57.

21. Zhai $Y$, Wang $W Z$, Zhao $W H$, et al. [The prevalence and onset of age of stroke in Chinese adults]. Zhonghua Yu Fang Yi Xue Za Zhi 2009;43:1069-72.

22. Zhang $X \mathrm{H}$, Guan T, Mao J, et al. Disparity and its time trends in stroke mortality between urban and rural populations in China 1987 to 2001: changing patterns and their implications for public health policy. Stroke 2007;38:3139-44.

23. Jun HJ, Kim KJ, Chun IA, et al. The relationship between stroke patients' socio-economic conditions and their quality of life: the 2010 Korean community health survey. J Phys Ther Sci 2015;27:781-4.

24. Allen J, Inder KJ, Harris ML, et al. Quality of life impact of cardiovascular and affective conditions among older residents from urban and rural communities. Health Qual Life Outcomes 2013;11:140

25. Dou J, Tang J, CH L. A study of suicidal ideation in acute ischemic stroke patients. Health and quality of life outcomes. Health and quality of life outcomes 2015;13:7-

26. Koifman J, Hall R, Li S, et al. The association between rural residence and stroke care and outcomes. J Neurol Sci 2016;363:16-20.

27. Yusuf S, Islam S, Chow CK, et al. Use of secondary prevention drugs for cardiovascular disease in the community in high-income, middle- income, and low-income countries (the PURE Study): a prospective epidemiological survey. The Lancet 2011;378:1231-43.

28. Li W, Gu H, Teo KK, et al. Hypertension prevalence, awareness, treatment, and control in 115 rural and urban communities involving 47000 people from China. J Hypertens 2016;34:39-46.

29. Cadilhac DA, Purvis T, Kilkenny MF, et al. Evaluation of rural stroke services: does implementation of coordinators and pathways improve care in rural hospitals? Stroke 2013;44:2848-53.

30. Swanoski MT, Lutfiyya MN, Amaro ML, et al. Knowledge of heart attack and stroke symptomology: a cross-sectional comparison of rural and non-rural US adults. BMC Public Health 2012;12:283.

31. Wiszniewska M, Głuszkiewicz M, Kobayashi A, et al. Knowledge of risk factors and stroke symptoms among nonstroke patients. Eur Neurol 2012:67:220-5.

32. Wang Y, Zhao X, Jiang Y, et al. Prevalence, knowledge, and treatment of transient ischemic attacks in China. Neurology 2015:84:2354-61.

33. Mi T, Sun S, Du Y, et al. Differences in the distribution of risk factors for stroke among the high-risk population in urban and rural areas of Eastern China. Brain Behav 2016;6:e00461.

34. Hickey A, Holly D, McGee H, et al. Knowledge of stroke risk factors and warning signs in Ireland: development and application of the Stroke Awareness Questionnaire (SAQ). International Journal of Stroke 2012;7:298-306.

35. Inoue Y, Honda S, Watanabe M, et al. Educational campaigns at point of purchase in rural supermarkets improve stroke knowledge. $J$ Stroke Cerebrovasc Dis 2015;24:480-4.

36. He M, Liu N, Ji N, et al. Effects of organized education by video on knowledge of Early stroke symptoms among a Chinese rural population. International Journal of Stroke 2014;9:E41.

37. He M, Wang J, Gong L, et al. Community-based stroke system of care for Chinese rural areas. Stroke 2014;45:2385-90.

38. Pit SW, Shrestha R, Schofield D, et al. Partial and complete retirement due to ill-health among mature age Australians. Public Health 2013;127:561-71

39. Howitt SC, Jones MP, Jusabani A, et al. A cross-sectional study of quality of life in incident stroke survivors in rural northern Tanzania. $J$ Neurol 2011;258:1422-30.

40. Wang $\mathrm{Q}$, Liu $\mathrm{H}$, Lu ZX, et al. Role of the new rural cooperative medical system in alleviating catastrophic medical payments for hypertension, stroke and coronary heart disease in poor rural areas of China. BMC Public Health 2014;14:907. 